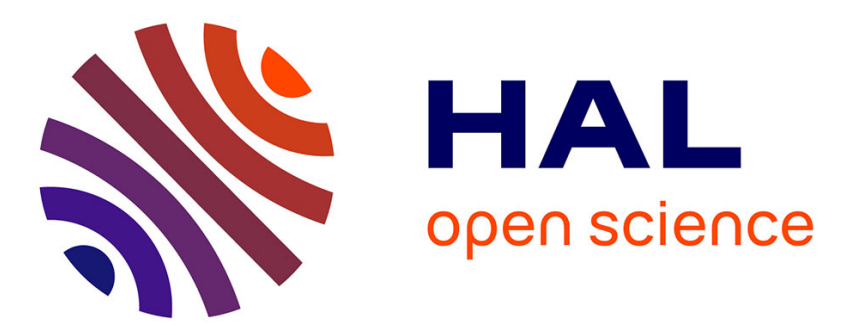

\title{
Numerical simulation of meso-gamma scale features of fohn at ground level in the Rhine valley
}

\author{
G. Jaubert, P. Bougeault, H. Berger, B. Chimani, Cyrille Flamant, C. \\ Haberli, Marie Lothon, M. Nuret, S. Vogt
}

\section{- To cite this version:}

G. Jaubert, P. Bougeault, H. Berger, B. Chimani, Cyrille Flamant, et al.. Numerical simulation of meso-gamma scale features of fohn at ground level in the Rhine valley. Quarterly Journal of the Royal Meteorological Society, 2005, 131 (608), pp.1339-1361. 10.1256/qj.03.197 . hal-00069274

\section{HAL Id: hal-00069274 \\ https://hal.science/hal-00069274}

Submitted on 10 Aug 2021

HAL is a multi-disciplinary open access archive for the deposit and dissemination of scientific research documents, whether they are published or not. The documents may come from teaching and research institutions in France or abroad, or from public or private research centers.
L'archive ouverte pluridisciplinaire $\mathbf{H A L}$, est destinée au dépôt et à la diffusion de documents scientifiques de niveau recherche, publiés ou non, émanant des établissements d'enseignement et de recherche français ou étrangers, des laboratoires publics ou privés. 


\title{
Numerical simulation of meso-gamma scale features of föhn at ground level in the Rhine valley
}

\author{
By G. JAUBERT ${ }^{1 *}$, P. BOUGEAULT ${ }^{1}$, H. BERGER $^{2}$, B. CHIMANI ${ }^{3}$, C. FLAMANT $^{4}$, \\ C. HÄBERLI ${ }^{5}$, M. LOTHON ${ }^{6}$, M. NURET ${ }^{1}$ and S. VOGT ${ }^{7}$ \\ ${ }^{1}$ CNRM/GAME, Météo-France, Toulouse, France \\ ${ }^{2}$ MétéoSuisse, Payerne, Switzerland \\ ${ }^{3}$ University of Vienna, Austria \\ ${ }^{4}$ Institut Pierre-Simon Laplace, Paris, France \\ ${ }^{5}$ MeteoSchweiz, Zurich, Switzerland \\ ${ }^{6}$ Laboratoire d'Aérologie, Lannemezan, France \\ ${ }^{7}$ Institut für Meteorologie und Klimaforschung, Karlsruhe, Germany
}

\begin{abstract}
This paper examines the impact of a mesoscale analysis ( $2.5 \mathrm{~km}$ grid distance) on the simulation of the mesogamma scale aspects of föhn in the Rhine Valley. The föhn event, documented during IOP15 (5 November 1999) of the Mesoscale Alpine Programme, was standard in terms of intensity and was characterized by an important temporal variability. Many instruments operating in the Rhine valley target area are used to validate the simulation, in particular the airborne nadir-pointing lidar LEANDRE 2 (flown over the lower Rhine valley) as well as a wind profiler and a radio accoustic sounding system collocated in Rankweil, Austria. The large observational dataset acquired during the IOP allowed documentation of the entire föhn life cycle. For most of the IOP, a cold pool remained near the ground in the lower northern part of the valley. The non-hydrostatic model Meso-NH, used in a grid-nesting configuration with two nested models and initialized with a mesoscale analysis, allowed us to simulate realistically the location and depth of the cold pool. The relationship between the föhn intensity and the large-scale environment is also examined. The flow regime is a 'flow around' the Alps. The variability of this flow at the western tip of the Alps could explain some of the temporal changes observed at low level in the Rhine valley.
\end{abstract}

Keywords: Cold pool Mesoscale analysis Mesoscale Alpine Program Mountain airflow

\section{INTRODUCTION}

Föhn conditions are observed on the northern side of the Alps when synoptic flow favours southerly or south-westerly winds in the low troposphere around the Alpine range, for instance upstream of a frontal system approaching from the west (Hoinka 1980). It results in a dry and warm southerly wind, sometimes severe downstream of the crests. Föhn occurs in a large variety of synoptic environments, from shallow föhn (Seibert 1990; Zängl 2002) where westerly flow at crest height is associated with south-westerly flow at low levels, to the deep föhn related to a strong southerly flow (Jaubert and Stein 2003). Associated flow regimes over the Alps are mainly related to flow splitting, or a mixed regime between flow splitting and wave breaking (see Schär 2002 for a review). The breakdown of the föhn occurs in association with the mesoscale changes, in many cases linked to the arrival of a frontal system. The effect of the föhn on cold fronts was studied by Hoinka (1987) and Heimann (1992). Interactions between fronts and the Alpine range have been analysed in the framework of the Front Experiment 1987 (Hoinka and Volkert 1992), where the acceleration of the flow at the north-western part of the Alps is mentioned. However, to our knowledge, very few studies have concerned the interaction of the flow around the Alps and the föhn flow, in the real case of a southerly flow.

The meso-beta scale aspects of these meteorological situations are nowadays simulated in real time by several operational numerical weather-prediction models in Europe,

\footnotetext{
* Corresponding author: CNRM/GAME, 42 Av. Coriolis, 31057 Toulouse Cedex, France. e-mail: genevieve.jaubert@meteo.fr
} 
with grid sizes close to $10 \mathrm{~km}$. These simulations are generally considered to be quite reliable. As demonstrated for instance during the Pyrenees Experiment (Bougeault et al. 1996), numerical models are able to predict the drying and warming effects associated with the subsidence downstream of major mountain ranges, as well as many aspects of the surface wind field and mountain waves. In contrast to these meso-beta scale aspects, little is known about the processes occurring at the meso-gamma scale inside the valleys themselves. Recent works using research models at a higher resolution pointed out the role of gaps, passes and/or valleys in channelling the flow, e.g. Saito (1993) for the yamaji-kaze in the Shikoku mountains, Colle and Mass (1998) for a windstorm observed in the Washington Cascade mountains, Zängl (2003) who performed semi-idealized simulations to study the föhn in the region of the Wipp valley in the Alps. Observations reveal that the floor of Alpine valleys is often occupied by a layer of cold air, created by radiative cooling during night-time. This 'cold pool' prevents the upper-level föhn flow from reaching the ground during most of the duration of föhn episodes. Only when föhn intensity is sufficient does the föhn flow touch the floor of Alpine valleys. Three mechanisms are likely to govern this penetration of the föhn flow to the valley floor (Gubser and Richner 2001):

(i) the diurnal heating of the cold pool by solar radiation may diminish the stability and allow vertical mixing,

(ii) turbulent entrainment induced by Kelvin-Helmholtz instability at the top of the cold pool may eventually destroy the pool (Nater et al. 1979), and

(iii) the occasional intensification of the mountain wave at the upper level may force the föhn flow down to the ground level, and flush the cold pool downstream, for instance in the case of a breaking wave aloft.

These three processes may also occur simultaneously.

The Special Observing Period (SOP) of the Mesoscale Alpine Programme (MAP, Bougeault et al. 2001) took place between 7 September and 15 November 1999. It was organized into eight Scientific Projects, among which the Föhn in the Rhine valley during MAP (FORM) project aimed to document the meso-gamma scale, non-stationary aspects of föhn episodes in the Rhine valley between Chur and Lake Constance (see Fig. 1). Available observing systems dedicated to this project comprised a network of surface measurements, numerous sounding stations, a radio-acoustic sounding system (RASS), a Doppler lidar, and several research aircraft. The objectives were to clarify the role of mechanisms (i)-(iii) listed above and to document the capability of present generation meso-gamma scale numerical models to simulate the detailed characteristics and evolution of föhn flows at the level of the valley floor.

Föhn events occurring in the framework of MAP have been studied by Jaubert and Stein (2003, IOP2*), Drobinski et al. (2003, IOP12), Zängl et al. (2004, IOP10), Lothon et al. (2003) and Beffrey et al. (2004, IOP8). In spite of their specific features linked to föhn intensity, these studies allowed the building of a comprehensive scheme of the temporal evolution of the föhn in a large valley, which is useful to validate numerical simulations.

The practical applications of numerical prediction of meso-gamma scale aspects of föhn inside a large Alpine valley are important, since föhn represents a major weather risk to all outdoor activities including air operations, and also influences air quality. Moreover, it is expected that this type of flow will offer one of the first opportunities for real-time, meso-gamma scale numerical weather prediction. Necessary ingredients for such a capability are assumed to be:

* Intensive Observation Period 2. 


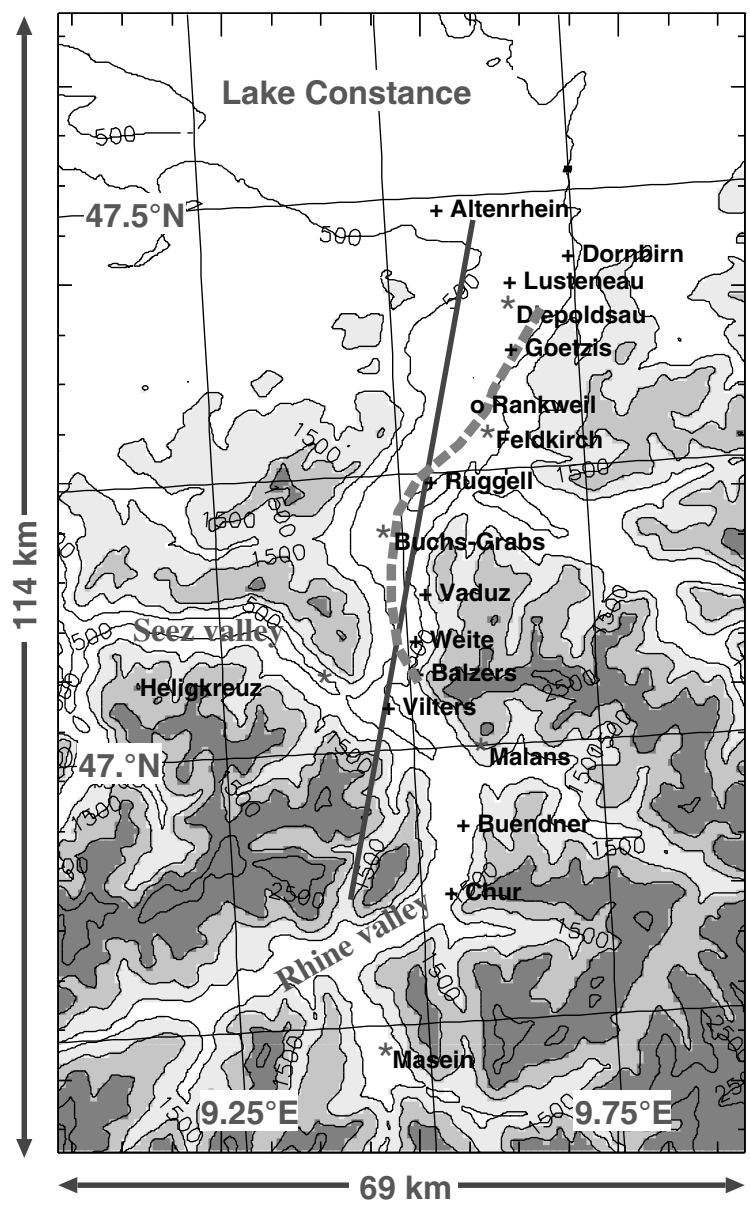

Figure 1. Terrain elevation in the Rhine valley area, with superimposed location of observation sites: sounding stations collocated with surface measurements (asterisks), surface measurements only (crosses), and RASS measurement (circle). The solid line shows the track of the research aircraft (ARAT and MERLIN) as they flew over the Rhine valley, and the dashed line shows the trajectory of the constant-volume balloon.

(i) a good simulation of larger-scale aspects, such as the upstream and downstream wind and stability,

(ii) a good initial analysis of low-level parameters inside the valley under consideration, and

(iii) a high-resolution model with a high-quality representation of orography, diurnal cycle and turbulence processes.

Previous work performed at Centre National de Recherches Météorologiques (CNRM) on data acquired in the framework of the FORM project provided evidence that a satisfactory simulation of the larger-scale aspects, as well as the meso-gamma aspects of the deep föhn case observed during IOP2 of MAP, can be achieved using operational meteorological analyses (supplied by the Météo-France ARPEGE* system) and the triply nested, non-hydrostatic model Meso-NH (Jaubert and Stein 2003). Using the same protocol, Beffrey et al. (2004) simulated the interaction of the cold pool and 
the föhn flow in the shallow föhn case of MAP IOP8. However, in these two studies, the depth of the cold pool was unrealistic, probably due to the weakness of the initial analyses. With a different numerical tool, Zängl et al. (2004) used the sounding measurements to modify the low levels of the large-scale analysis close to the Alps in order to get a more realistic surface temperature, particularly in the Rhine valley. The purpose of the present paper is to go one step further and explore the benefits of introducing some mesoscale features, such as the presence of a cold pool, at the valley scale, using an operational mesoscale analysis scheme. The case under study here is IOP15 (5-6 November 1999), one of the best event of the whole field experiment. We focus on:

(i) the simulation of surface-level parameters inside the valley, in relationship with the vertical structure of the cold pool, and

(ii) the temporal evolution of the flow over 18 hours (covering the entire föhn event) at a specific location (i.e. Rankweil where a wind profiler and a RASS were collocated), to verify the accuracy of the model initialization at small scale.

The influence of the evolution of the flow over and around the Alps on the intensity of the föhn in the Rhine valley is also explored.

In section 2, we briefly present the numerical model, the objective analysis method and the synoptic situation. Section 3 presents the available observations on IOP15 and their use for validating high-resolution numerical simulations. Section 4 discusses the influence of the flow intensity and direction over the foothills on the temporal changes of the föhn flow in the valley.

\section{CHARACTERISTICS OF THE SIMULATIONS AND SYNOPTIC CONDITIONS}

\section{(a) Model}

The French community non-hydrostatic meso-scale model Meso-NH (Lafore et al. 1998 ) is used in this study. Two nested domains are used with the two-way interactive grid-nesting technique described by Stein et al. (2000). The outer domain covers western Europe with a $10 \mathrm{~km}$ grid size, while the inner domain covers the Alpine region with a $2.5 \mathrm{~km}$ grid size (see Fig. 2). The domains and physical parametrizations are the same as those used by Jaubert and Stein (2003), except for the use of the most recent radiation scheme of the European Centre for Medium-Range Weather Forecasts (Morcrette et al. 2001). This scheme accounts for aerosols and provides better infrared and solar radiation fluxes, a point of importance for the diurnal evolution of the cooling in the valleys. A fourth-order horizontal numerical diffusion is applied to the difference between the actual variable and a reference profile. The numerical diffusion intensity in the inner model in this study is reduced by a factor of three compared to the previous studies of Jaubert and Stein (2003), Beffrey et al. (2004) and Vogt and Jaubert (2004). This tuning improves the simulation of the cold pool, in accordance with the sensitivity experiments of Zängl et al. (2004) for the IOP10 MAP föhn case. In particular, it improves the föhn break intensity for the IOP15 simulations presented here. Lateral boundary conditions are provided by time-space interpolation between operational analyses of the ARPEGE system of Météo-France, available every 6 hours.

\section{(b) Initial conditions}

Four different initial conditions are considered. The reference simulations (REF00 and REF12) are initialized by the ARPEGE analysis valid at 00 and 12 UTC on 5 November 1999. Simulations A00 and A12 are initialized by mesoscale analyses valid at 00 and 12 UTC on 5 November 1999. The mesoscale analysis is performed on both 

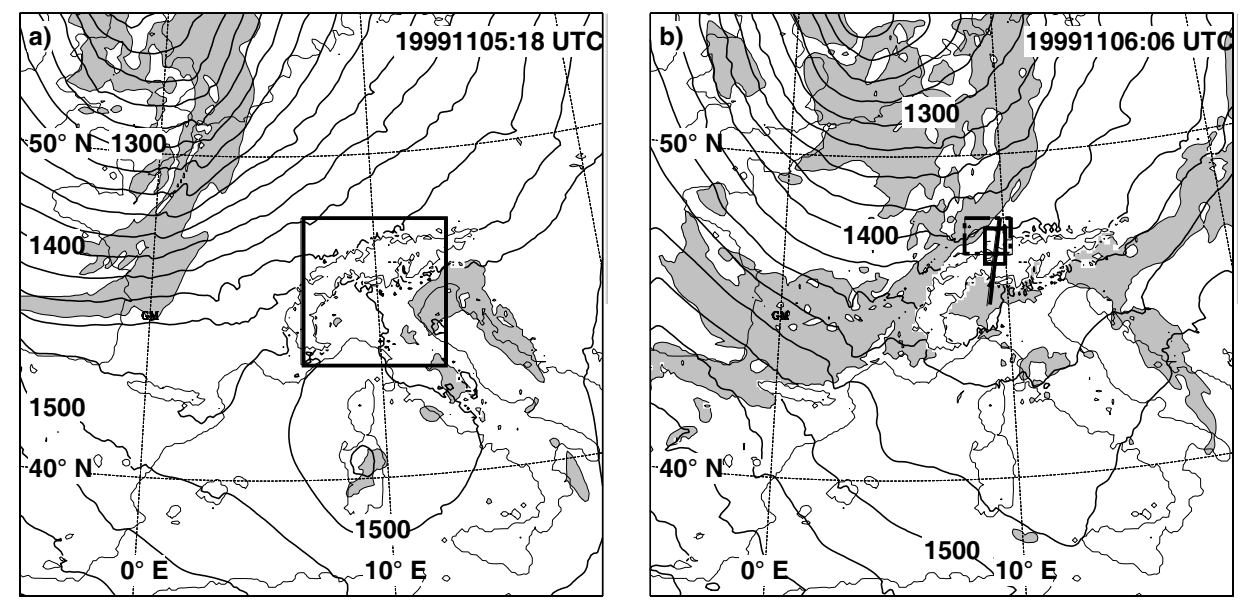

Figure 2. Geopotential heights (contours, $20 \mathrm{~m}$ interval) and humidity over $90 \%$ (shading) at $850 \mathrm{hPa}$ from the A12 run at (a) 18 UTC on 5 November and (b) 06 UTC on 6 November 1999. Thin lines show terrain elevation at 0 and $1500 \mathrm{~m}$, and the figure covers the domain of the $10 \mathrm{~km}$ mesh model. In (a), the square denotes the area of the $2.5 \mathrm{~km}$ mesh model. In (b), the smaller rectangle shows the area covered by Fig. 1, the larger rectangle that by

Figs. 13 and 15, and the bold line indicates the line of the cross-section in Fig. 14.

TABLE 1. TUNING OF THE MESOSCALE ANALYSIS STATISTICAL MODEL

\begin{tabular}{lcccccc}
\hline & \multicolumn{2}{c}{$\begin{array}{c}\text { Standard error of } \\
\text { the guess }\left(\sigma_{\mathrm{g}}\right)\end{array}$} & & \multicolumn{2}{c}{$\begin{array}{c}\text { Standard error of } \\
\text { the observations }\left(\sigma_{\mathrm{o}}\right)\end{array}$} \\
\cline { 2 - 3 } \cline { 6 - 7 } \cline { 5 - 6 } Parameter & Surface & Altitude & & Surface & Altitude \\
\hline Temperature $(\mathrm{K})$ & 2 & 2 & & 1.4 & 1.5 \\
Humidity $(\%)$ & 15 & 20 & & 10 & 12 \\
Wind speed $\left(\mathrm{m} \mathrm{s}^{-1}\right)$ & 6 & 3 to 4 & & 2 & 2 to 3 \\
Geopotential height $(\mathrm{gpm})$ & & 70 to 300 & & 8 & 8 to 16 \\
\hline
\end{tabular}

the $10 \mathrm{~km}$ and $2.5 \mathrm{~km}$ domains. It uses all the available operational surface stations and sounding observations, together with the additional ones acquired specifically during MAP. For example, for the $2.5 \mathrm{~km}$ domain, 129 observations are actually used for the analysis at 12 UTC. These include twelve soundings, of which seven are located within the Rhine valley. Most of the surface stations provide $2 \mathrm{~m}$ temperature, $2 \mathrm{~m}$ humidity and $10 \mathrm{~m}$ wind measurements. Observations of surface pressure are fewer. The analysis tool is based on the CANARI/DIAGPACK optimal interpolation scheme that has been tuned for the mesoscale (Calas et al. 2000; Ducrocq et al. 2000, 2002). Such a mesoscale analysis scheme is used operationally at Météo-France to produce spatial interpolation of automatic surface observations over plains and low-elevation terrain on a $10 \mathrm{~km}$ grid (Bouyssel et al. 2002). It provides analysed fields of upper-air wind, temperature and humidity, as well as $10 \mathrm{~m}$ wind, $2 \mathrm{~m}$ temperature and humidity and sea-level pressure. The vertical resolution of the analysis consists of 31 levels, with 10 levels between $20 \mathrm{~m}$ and $2 \mathrm{~km}$ above ground. For our simulations, the initial guess is provided by the ARPEGE analysis valid at the same time. According to the high density of the network, we use the same observation and guess-field error statistics as those tuned for mesoscale applications of CANARI/DIAGPACK (see Table 1). No additional tuning has been performed to account for use in mountainous regions. The same statistics are used for the $10 \mathrm{~km}$ and $2.5 \mathrm{~km}$ domains. The tuning of the characteristic lengthscale of the background error allows the presence in the mesoscale analysis of 'meso- $\beta$ ' 


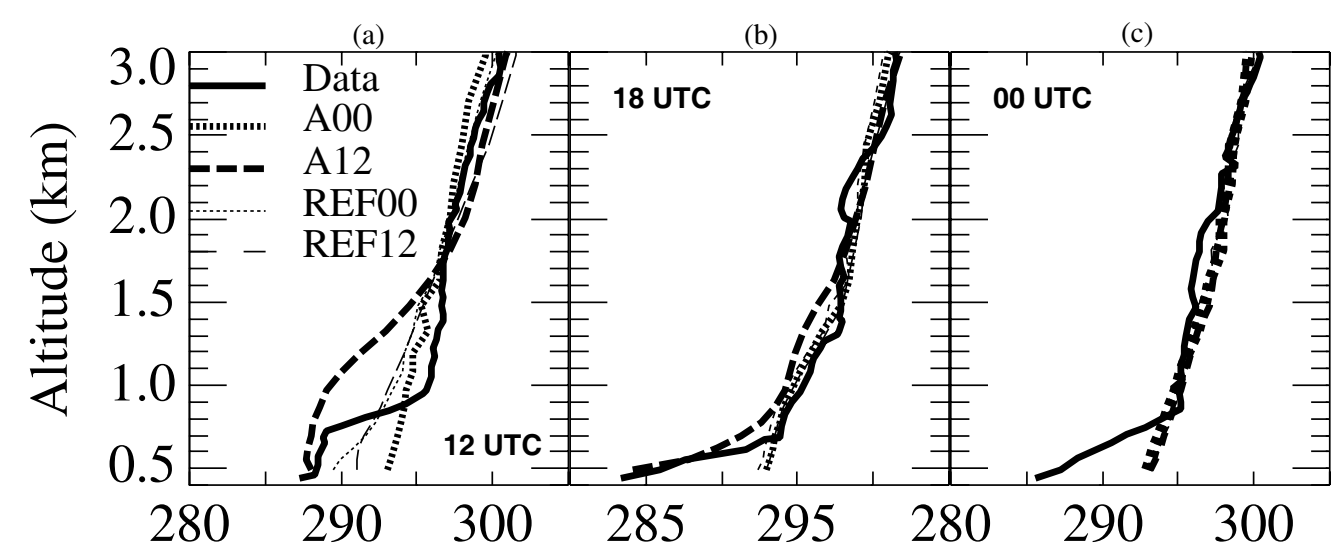

Figure 3. Vertical profiles of potential temperature (K) at Buchs-Grabs at (a) 12 UTC and (b) 18 UTC on 5 November, and (c) at 00 UTC on 6 November 1999, as measured by balloon sounding (solid) and extracted from four different simulations (see text).

(a)

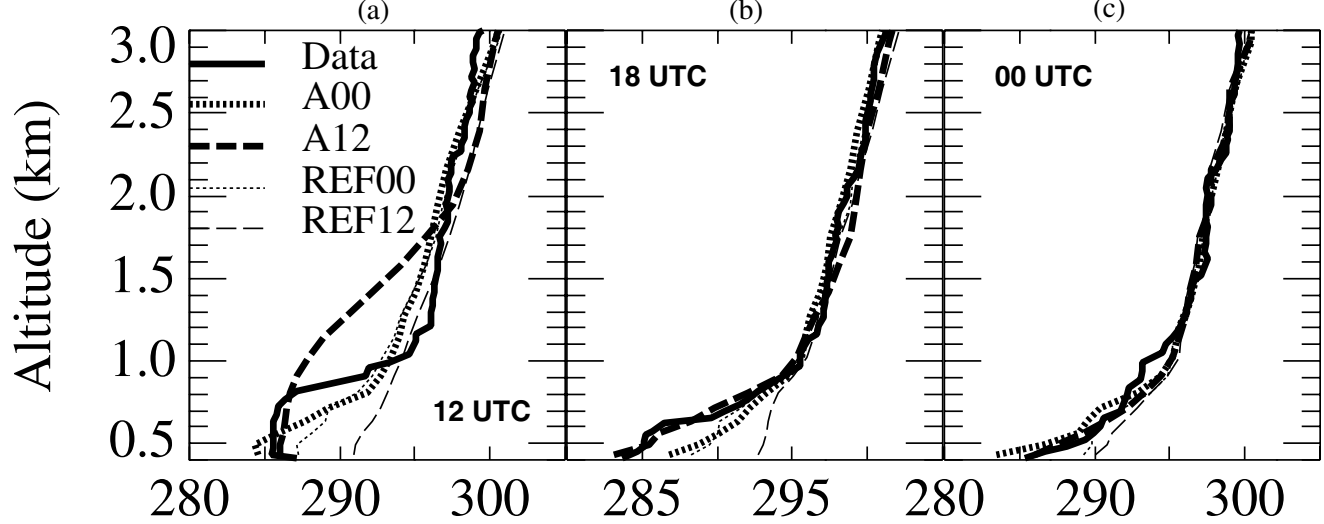

Figure 4. As Fig. 3, but for Diepoldsau.

scale features such as the cold pool. This length is set at the surface to $60 \mathrm{~km}$ for the temperature and humidity analyses, $100 \mathrm{~km}$ for the wind analysis, and $200 \mathrm{~km}$ for the surface pressure. These values increase with height for the altitude analysis. Surfacelevel observations influence upper-air parameters up to $150 \mathrm{hPa}$ above the surface, due to the prescribed vertical correlation structure function. This vertical length-scale has been chosen to ensure that, on average, surface observations impact on the planetary boundary layer only. Surface observations from stations higher than $1500 \mathrm{~m}$ above sea level were rejected, as well as those showing a difference larger than $800 \mathrm{~m}$ between the model orography and the station height.

The initial states of the simulations REF12 and A12 are compared in Figs. 3(a) and 4(a) with the 12 UTC Buchs-Grabs and Diepoldsau soundings in the Rhine valley. Cooling above the ground surface is completely missed in the ARPEGE 12 UTC (REF12), as the narrow valley is not represented by the coarse resolution of the ARPEGE analysis. Conversely, the low-level cooling is depicted in the mesoscale analysis with a correct magnitude near the surface, thanks to the detailed orography 
available on the $2.5 \mathrm{~km}$ grid and the mesoscale observation analysis. However, the top of the cold pool is too high and the thickness of the interface between the cold pool and the warmer air of the föhn jet is too large; the operational tuning of the mesoscale analysis has some difficulties in describing large vertical gradients such as those observed at the top of a cold pool.

\section{(c) Synoptic situation}

Geopotential maps at $850 \mathrm{hPa}$ valid at 18 UTC 5 November and at 06 UTC 6 November are shown in Fig. 2. The main low was moving towards the east over northern Europe, generating a secondary low, centred on Sardinia at 18 UTC 5 November and hardly visible the following day. A related frontal system reached the upper Rhine valley at 06 UTC on 6 November. To the north of the Alps, the winds were from the west-south-west during this period. To the south of the Alps, the winds were from the south-east at first, then veering to south-west. These are paradigmatic föhn conditions.

\section{COMPARISON OF SIMULATIONS WITH OBSERVATIONS}

\section{(a) Observations used in this study}

Special observations available during MAP in the Rhine valley consisted of seven additional sounding stations (operated by the Swiss Army) and a dense network of surface stations giving hourly measurements. A subset of these stations (shown in Fig. 1) has been used to conduct the spatio-temporal analysis of the föhn characteristics at ground level inside the Rhine valley, shown in Fig. 5. Around 15 UTC on 5 November, the Rhine valley was overflown by the two French research aircraft, the Merlin IV of Météo-France and the multi-agency ARAT (Avions de Recherche Atmosphérique et Télédétection). The latter was equipped with the nadir-pointing water vapour differential absorption lidar LEANDRE 2. The UHF-RASS system of the Institut für Meteorologie und Klimaforschung was also operating from the ground within the valley (Vogt and Jaubert 2004). This radar has a five-beam geometry for two bi-static radio-frequency and acoustic antennae. Both antennae emit continuous waves that are frequency modulated with a saw-tooth pattern (FM-CW-Doppler Radar) and provide high average transmitted power. Thanks to this unique design, redundant wind profiles are derived from both the UHF and RASS signal with high resolution in time and height. The temperature profile is estimated simultaneously from the RASS signal. Finally, several constant-level balloons were launched by MeteoSwiss and the Laboratoire d'Aérologie from Malans on 5 November; these flew over the Rhine valley, providing observations of air-mass trajectory, wind, temperature, humidity and pressure.

\section{(b) The föhn episode in the Rhine valley}

The observations of potential temperature, wind speed (northward component) and surface pressure from the surface network have been used to construct the Hovmüller diagram shown in Fig. 5(a)-(c). Data are interpolated using an inverse-distance averaging technique. They show the complex evolution of the föhn episode at the valleyfloor level. First, a temperature maximum is evident throughout the valley from 10 to 18 UTC on 5 November. Additional warming for Chur to Malans is well correlated with the southerly wind and provides evidence for the föhn, which starts in the upper Rhine valley (south of Malans) at 12 UTC on 5 November. From this time, until 15 UTC, there is no evidence of föhn at ground level in the lower Rhine valley, except near Balzers. Weak northerly winds are observed north of Vaduz, which are the signature of the cold pool. 

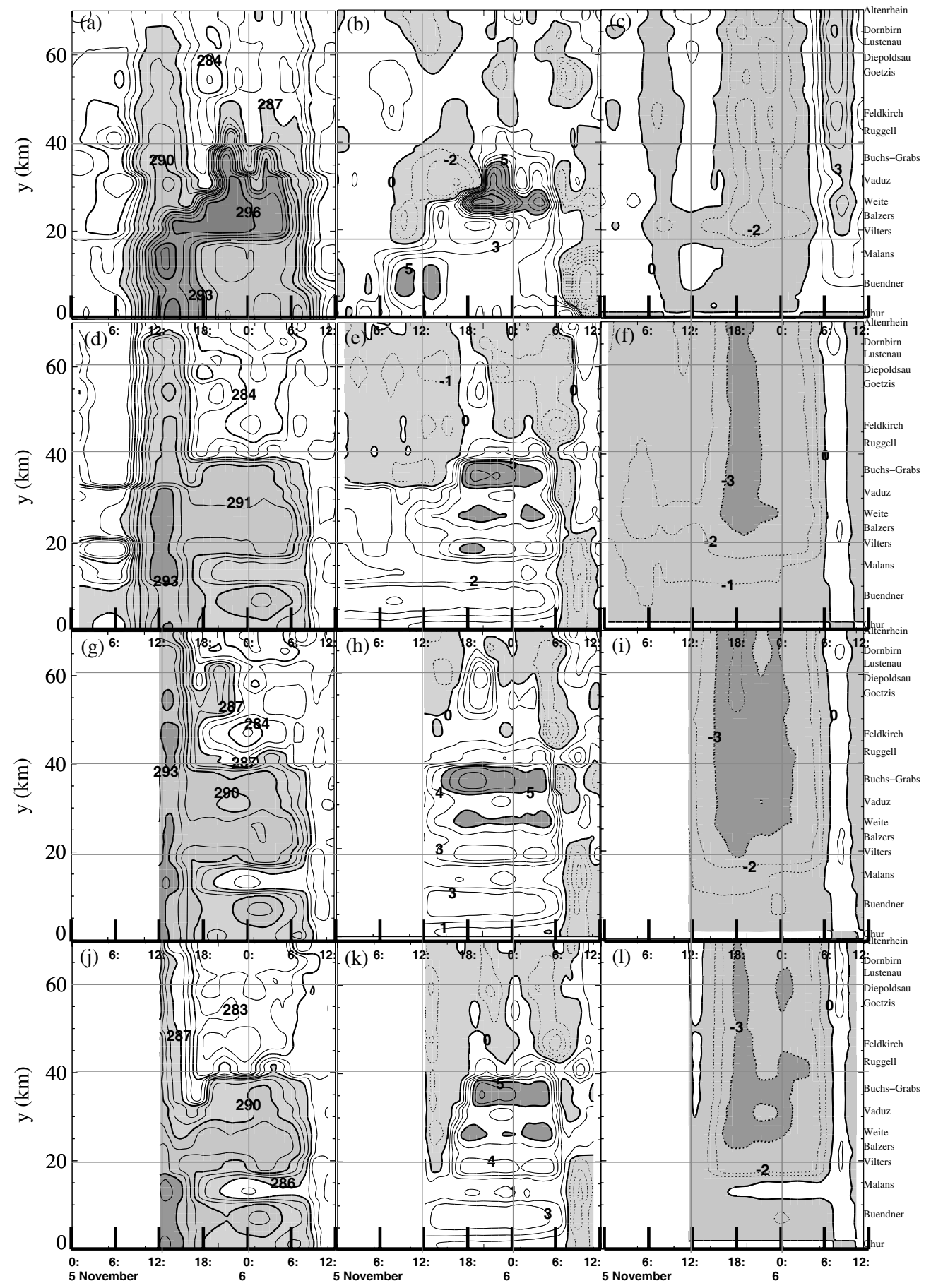

Figure 5. Hovmüller diagram of the surface parameters between 00 UTC 5 November and 12 UTC 6 November 1999 , in the Rhine valley between Chur $\left(46.74^{\circ} \mathrm{N}\right)$ and Altenrhein $\left(47.48^{\circ} \mathrm{N}\right)$ : (a) potential temperature, with contour interval $1 \mathrm{~K}$ and shading above $287 \mathrm{~K}$, (b) northward component of wind speed, with contour interval $1 \mathrm{~m} \mathrm{~s}^{-1}$, light shading below $0 \mathrm{~m} \mathrm{~s}^{-1}$, and dark shading above $5 \mathrm{~m} \mathrm{~s}^{-1}$, and (c) difference in reduced pressure at $430 \mathrm{~m}$ above mean sea level between each station and Chur, with light shading above $0 \mathrm{hPa}$, medium shading from 0 to $-3 \mathrm{hPa}$, and dark shading below $-3 \mathrm{hPa}$. (d)-(f), (g)-(i), (j)-(l) are as (a)-(c), but from REF00, REF12, and A12 simulations, respectively. 
(a)

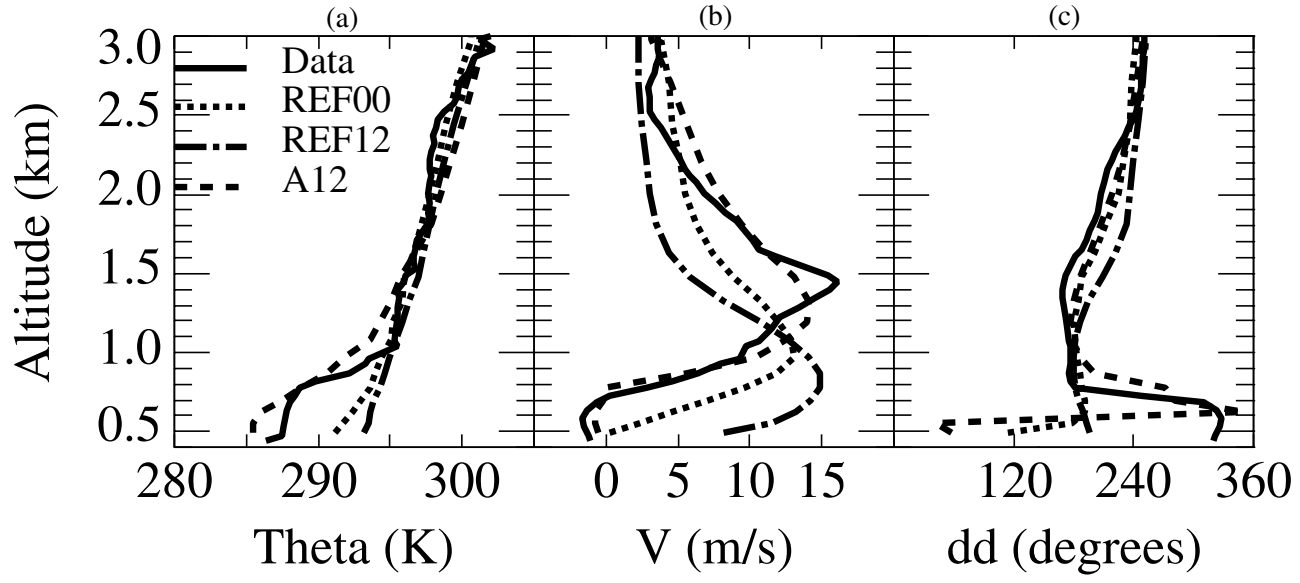

Figure 6. Vertical profiles at Buchs-Grabs at 15 UTC on 5 November 1999 of (a) potential temperature, (b) northward wind speed component and (c) wind direction, from balloon sounding measurement (solid) and from three simulations.

Indeed, the sounding taken at Buchs-Grabs at 15 UTC (Fig. 6) clearly shows a $300 \mathrm{~m}$ deep cold pool surmounted by a $15 \mathrm{~m} \mathrm{~s}^{-1}$ föhn jet at $1.5 \mathrm{~km}$ above mean sea level. In fact, the föhn jet at ground level leaves the Rhine valley at Vilters to enter the Seez valley, as already discussed by Beffrey et al. (2004) in the case of IOP8. This ensures mass conservation. However, the increase of temperature, associated with southerly wind at Balzers at 14 UTC, could indicate that part of this air comes in the lower Rhine valley. After 15 UTC, the föhn intensity diminishes in the upper valley (south of Malans), but increases in the lower part of the valley; the föhn reaches the ground near 18 UTC at Weite and 19 UTC at Buchs-Grabs. During this episode, the cold pool is pushed towards Diepoldsau (Figs. 3(b) and 4(b)). The föhn then rapidly weakens between 22 UTC on 5 November and 00 UTC on 6 November. A second wind maximum is observed between 01 and 06 UTC on 6 November, then the wind decreases rather abruptly. The pressure field is rather flat along the valley and everywhere lower than at Chur during the föhn event. However, after 06 UTC on 6 November, the pressure rises by about $3 \mathrm{hPa}$ in the whole valley and a northerly wind signals the arrival of a cold air mass from the north. This is the end of the föhn episode of IOP15.

Similar parameters have been plotted from simulations REF00, REF12 and A12 (Fig. 5(d)-(1)). For that purpose, simulation results have been extracted at the location of the observations and interpolated, as for the observations. The three simulations reproduce reasonably well the main patterns discussed above. The simulations reproduce the higher temperature in the whole valley around noon, and the temperature maximum during the föhn event in the southern part of the lower Rhine valley, south of Ruggell. However, the föhn intensity south of Malans is underestimated at the beginning of the föhn episode. Later the simulations capture well the time evolution of the wind near Weite, despite an underestimation of its intensity. Likewise, the potential temperature where the föhn reaches the ground is underestimated by $5 \mathrm{~K}$. One reason may be the very poor description of the $3 \mathrm{~km}$ wide valley at Weite by the $2.5 \mathrm{~km}$ grid model. The northerly wind which occurs near Diepoldsau during the episode is well simulated. The föhn weakening between 22 and 00 UTC is present in the three simulations, as well as the föhn break in connection with the arrival of the cold-air front. However, the surface signature of the föhn differs slightly between the three simulations. 
The REF12 simulation is too warm until 22 UTC, and the föhn reaches the ground between Balzers and Ruggell from 14 UTC on 5 November to 06 UTC on 6 November, and as far as Dornbirn between 18 and 22 UTC. The A12 simulation is close to the REF00 simulation; both produce temperatures which are too low over the northern part of the valley, with A12 having slightly greater temperature error. In contrast, A12 better simulates the föhn area before 00 UTC by limiting it to the south of Goetzis, and after 00 UTC by showing a more marked föhn.

This can be explained by the fact that the cold pool was better depicted in the initial conditions of simulation A12. Indeed, as seen in Fig. 6, the cold-pool depth at BuchsGrabs at 15 UTC is reasonably well captured by A12, whereas the cold pool is not present in REF00 and REF12. The upper föhn jet above the cold pool is also remarkably well captured in simulation A12 and the error in wind direction is reduced. At 18 UTC (Fig. 3), the sounding shows that the cold pool has disappeared; the cooling is limited to the ground surface, surmounted by a $200 \mathrm{~m}$ transition zone characterized by large vertical temperature gradients. Simulation A12 succeeds in simulating this transition zone near the ground, whereas REF00 and REF12 fail to reproduce it. The sounding launched at Diepoldsau at the same time (Fig. 4(b)) still shows a cold pool $250 \mathrm{~m}$ deep, surmounted by a $250 \mathrm{~m}$ transition zone, near the outlet of the valley. Simulation A12 reproduces correctly both the cold pool and the transition zone. In contrast, the cold pool is too warm in REF00, and is missed completely in REF12. At 00 UTC on 6 November, the föhn intermittence is depicted in the three simulations at Diepoldsau (Fig. 4(c)), but not at Buchs-Grabs (Fig. 3(c)).

The time-height cross-sections of potential temperature and northward wind component obtained by the RASS at Rankweil (Fig. 7, see location on Fig. 1) confirm the overall quality of the simulations. During the morning of 5 November, the depth of the cold pool observed at Rankweil diminishes slowly at first, and then more rapidly between 07 and 09 UTC, then reaching $250 \mathrm{~m}$. The cold pool is separated from the föhn layer ( $7 \mathrm{~K}$ warmer) by a $300 \mathrm{~m}$ deep transition zone. The wind has a small southerly component. In the meantime, the wind speed near the ground surface has increased, with a southerly flow of $4 \mathrm{~m} \mathrm{~s}^{-1}$ around noon. The same conditions prevail until 17 UTC, when the depth of the cold pool again start diminishing abruptly, leading to a föhn touchdown at approximately 19 UTC on 5 November. The cold pool reappears briefly between 22 and 00 UTC (light northerly wind, lower potential temperature), followed by a second föhn episode at the ground until 06 UTC on 6 November, when the föhn layer is pushed back aloft. The föhn episode is then brought to an end by the arrival of the moist perturbation on the northern side of the Alps, around 06 UTC. REF00 and A12 simulations capture the overall evolution of the time-height cross-sections quite well, but only simulation A12, benefiting from the most recent and detailed observations inside the valley, is able to capture with a good intensity the short föhn break in the middle of the night. The REF simulations, already compared with the RASS measurements in Vogt and Jaubert (2004), initialized with the same analysis as simulation A12 but computed with a larger coefficient for the numerical diffusion, allow the capture the föhn break, but with a weaker intensity.

\section{(c) A cross-section of the cold pool at 15 UTC 15 November}

The vertical structure of the cold pool has been documented from reflectivity measurements made along the Rhine valley between 1445 and 1505 UTC by the nadirpointing differential absorption lidar LEANDRE 2 (Fig. 8), flying on board the ARAT aircraft. The lidar reflectivity depends on the relative humidity and aerosol concentration (Flamant et al. 2002). In the reflectivity measurements, the cold pool is identified as the 
(a)
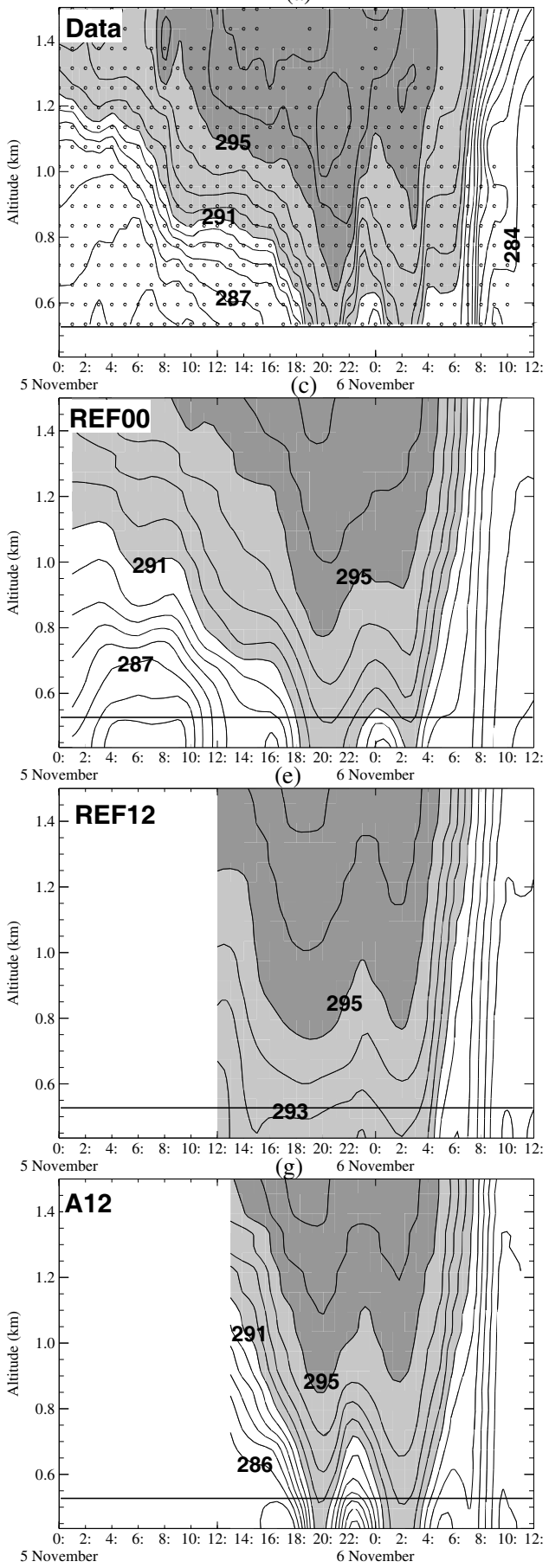

(b)
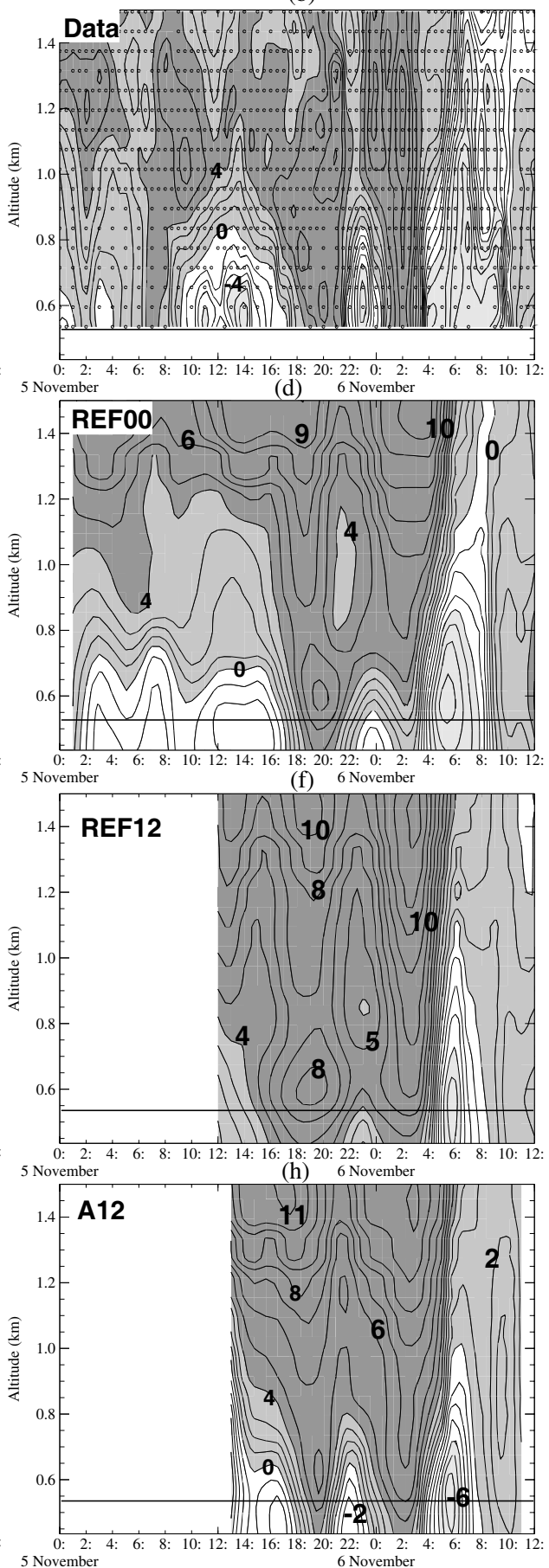

Figure 7. Time-height cross-section from RASS measurements of (a) potential temperature (contour interval $1 \mathrm{~K}$, light shading above $291 \mathrm{~K}$ and darker shading above $295 \mathrm{~K}$ ), and (b) northward component of the wind (contour interval $1 \mathrm{~m} \mathrm{~s}^{-1}$, with lighter shading below $-4 \mathrm{~m} \mathrm{~s}^{-1}$, medium shading above $0 \mathrm{~m} \mathrm{~s}^{-1}$, and darker shading above $4 \mathrm{~m} \mathrm{~s}^{-1}$ ) at Rankweil in the Rhine valley. The locations of the measurements are indicated by small circles, and the thin horizontal line indicates the lowest limit of the RASS measurements. (c)-(d), (e)-(f), (g)-(h) are as (a)-(b), but from simulations REF00, REF12, and A12, respectively. 


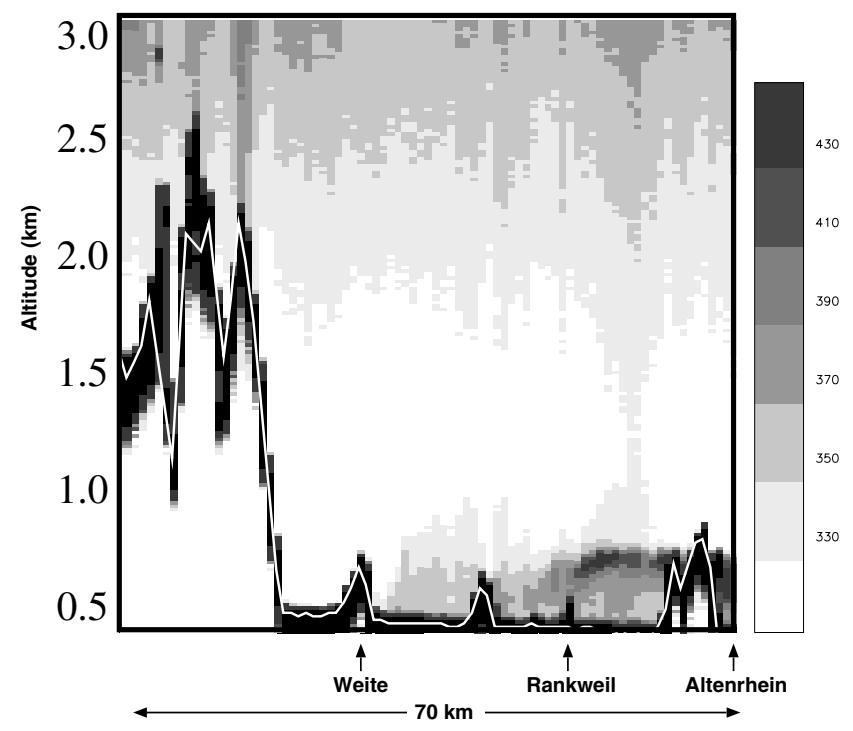

Figure 8. Atmospheric reflectivity at $732 \mathrm{~nm}$ as obtained from LEANDRE 2 between 1445 and 1505 UTC on 5 November 1999 along the solid line shown in Fig.1. Reflectivity units are arbitrary. The continuous white line represents the orography.

region of high reflectivity (350 arbitrary units or higher). Above the cold pool and below $2 \mathrm{~km}$ amsl, the reflectivity is generally very low, indicating the presence of the dry föhn layer. The southern tip of the cold pool is located just north of Weite, in agreement with the surface measurements. The depth of the cold pool increases slowly to the north, and reaches $250 \mathrm{~m}$ north of Rankweil, where the reflectivity also increases, indicating moister conditions (provided that aerosol number concentration is unchanged). This depth was also observed over Lake Constance (not shown, see Flamant et al. 2003).

Relative humidity fields for the three simulations along the ARAT flight track are shown in Figs. 9(c), (f), (i) and (1). The structure of the cold pool, as defined by relative humidity above $70 \%$, bears resemblance to that observed by lidar in simulation A12, however the cold pool is too thin in simulation REF00, and missing in simulation REF12.

Finally, we propose a composite picture (Fig. 10) of the potential temperature and northward component of the wind around $15 \mathrm{UTC}$, based on all the observations available near and along the research flight track, i.e. the 15 UTC surface observations, 15 UTC radiosoundings launched at Malans, Buchs-Grabs, Feldkirch and Diepoldsau, constant-volume balloon launched at Malans at 1522 UTC (trajectory on Fig. 1), Merlin aircraft legs over the Rhine valley (1533-1613 UTC) and Rankweil profiler measurements. To build the composite, the data positions are projected onto the vertical plan defined by the track of the research aircraft (see Fig. 1), and then the data are spatially interpolated over this plan using an inverse-distance averaging technique. When interpreting the composite, one must be aware that it gives only an approximate picture of the phenomena in the valley since the data are not all in the vertical plane of the flight track. This composite picture shows a cold-pool depth of about $300 \mathrm{~m}$, with a temperature difference between the cold pool and the föhn layer about $8 \mathrm{~K}$. A slight northerly wind component at the centre of the cold pool is also discernible. In contrast, a southerly jet 


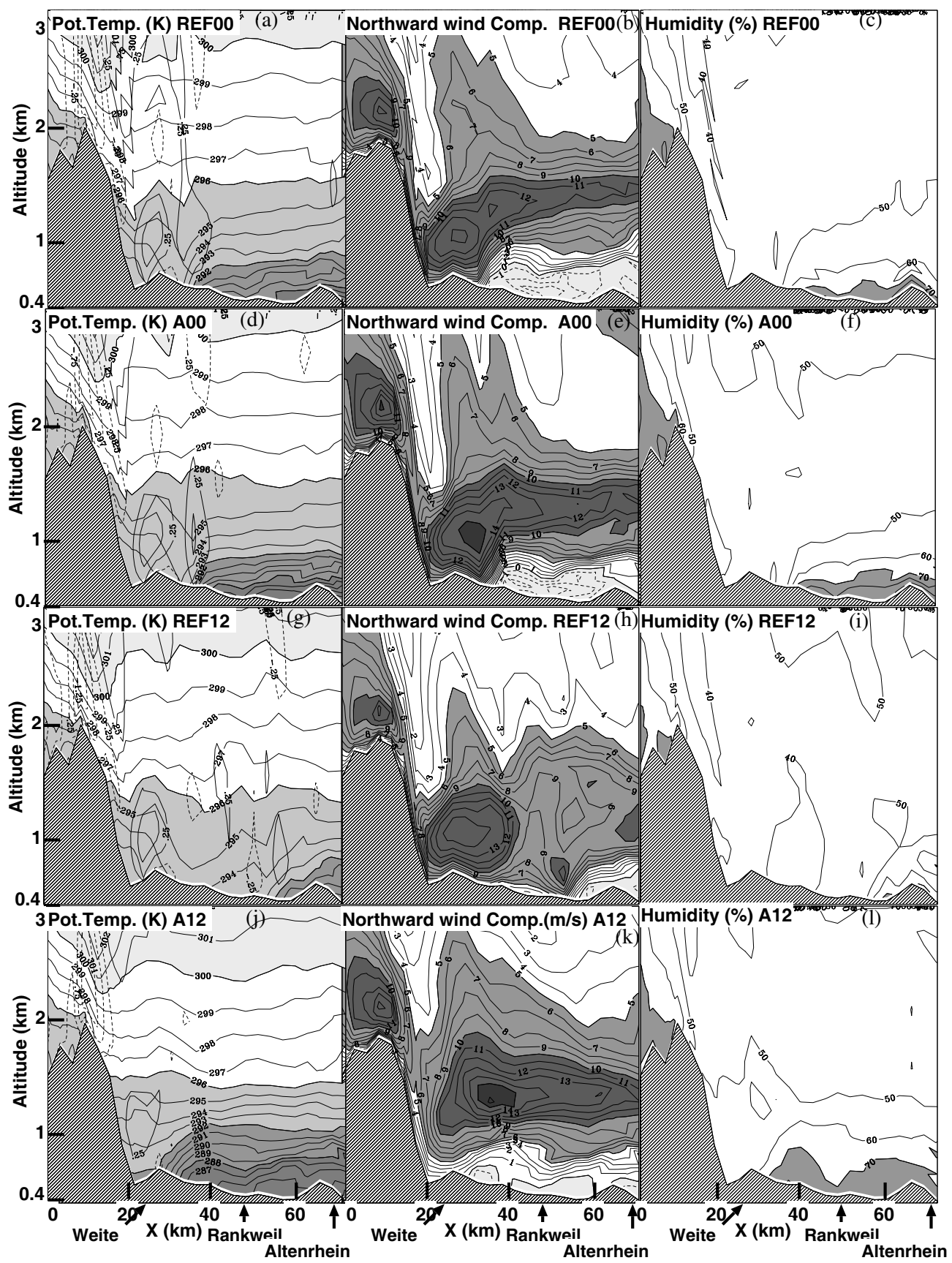

Figure 9. Vertical cross-section (along line shown in Fig.1) from the REF00 simulation at 15 UTC on 5 November 1999 of (a) potential temperature (with contour interval $1 \mathrm{~K}$, light shading for over $300 \mathrm{~K}$, medium shading below $296 \mathrm{~K}$, and darker shading below $292 \mathrm{~K}$ ) and vertical velocity (dashed contour interval $0.25 \mathrm{~m} \mathrm{~s}^{-1}$ ), (b) northward component of wind speed (contour interval $1 \mathrm{~m} \mathrm{~s}^{-1}$, with light shading below $0 \mathrm{~m} \mathrm{~s}^{-1}$, medium shading above $5 \mathrm{~m} \mathrm{~s}^{-1}$, and darker shading above $10 \mathrm{~m} \mathrm{~s}^{-1}$ ), and (c) relative humidity (with contour interval $10 \%$, and shading above 70\%). (d)-(f), (g)-(i), (j)-(1) are as (a)-(c), but for A00, REF12, and A12 simulations, respectively. 
(a)

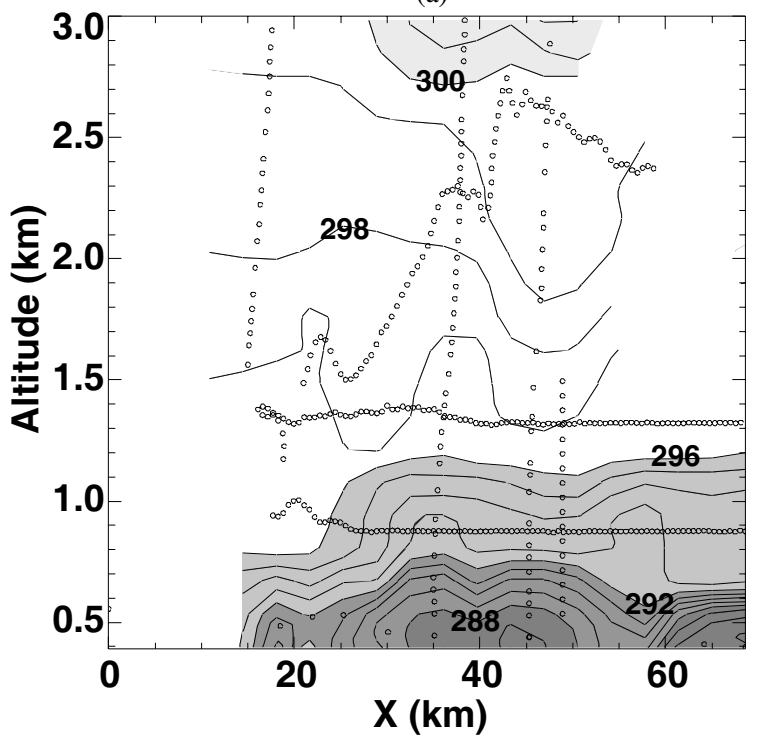

(b)

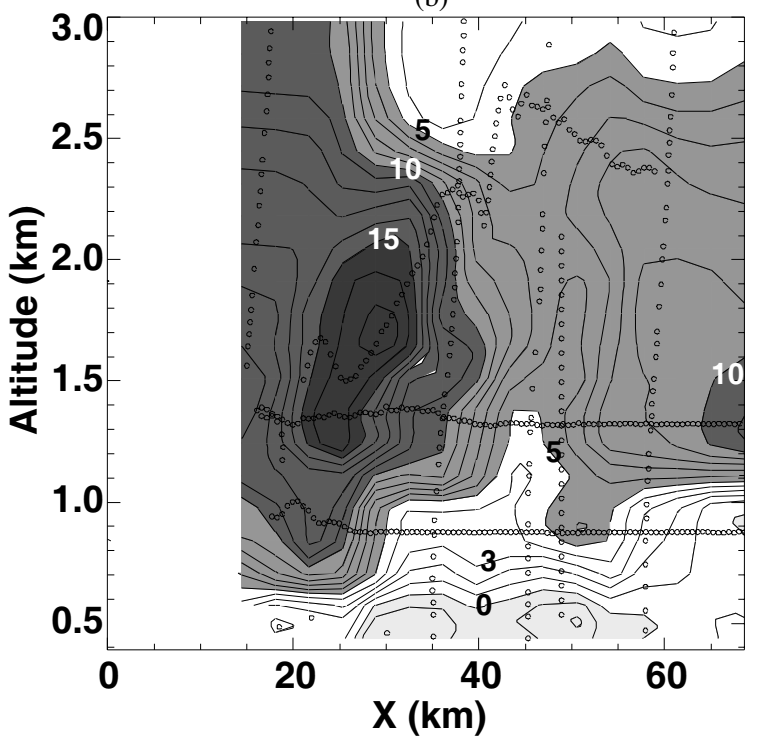

Figure 10. Vertical cross-section in the Rhine valley between Malans and Altenrhein at 15 UTC on 5 November 1999 of (a) potential temperature and (b) northward component of the wind, composited from surface measurements, radiosoundings launched at Malans, Buchs-Grabs, Feldkirch and Diepoldsau, constant-volume balloon launched at Malans, Merlin aircraft legs over the Rhine valley and Rankweil profiler measurements. The locations of the measurements are indicated by small circles. Contours and shading are as in Figs. 9(a) and (b).

reaching $17 \mathrm{~m} \mathrm{~s}^{-1}$ characterizes the föhn layer, with some subsidence in its southern flank as evidenced by the constant-volume balloon trajectory.

Most of the features seen on Fig. 10 are reproduced by the simulations (Fig. 9). However, REF00 and A12 give a closer picture than REF12, with again a small advantage for A12 over REF00. For example, the cold pool in A12 extends further southwards as in the observed composite picture, and the föhn only just touches the 
ground in A12 whereas the touchdown is more pronounced in REF00. The vertical velocity in Fig. 9 shows a strong downdraught just downstream of the main slope $\left(-0.75 \mathrm{~m} \mathrm{~s}^{-1}\right)$ and a double updraught for REF12 and REF00. The first updraught is due to a low-level jet connecting the upper Rhine valley and the Seez valley, resembling the pattern described in detail by Beffrey et al. (2004). The second updraught is induced by the cold pool that forces the föhn jet aloft. In A12, the two updraughts have merged into a single updraught, due to the close location of the southern tip of the cold pool and of the bifurcation towards the Seez valley.

\section{(d) Duration of the benefit of the mesoscale initialization}

The mesoscale analysis performed at 12 UTC improves the simulation, in particular during the first twelve hours. To evaluate the duration of the benefit of the mesoscale initialization over a longer period, vertical profiles from the simulation initialized with the A00 mesoscale analysis at 00 UTC are provided at Buchs-Grabs (Fig. 3) and Diepoldsau (Fig. 4). At Buchs-Grabs, results from the A00 simulation are very similar to the REF00 and REF12 results, except at 12 UTC where the föhn reaches the ground too early with respect to the measurements. In contrast, at Diepoldsau at 12 UTC, the cold pool is colder in A00 than in REF00, even if it is not deep enough. At 00 UTC on 6 November, twenty-four hours after the simulation began, the colder northerly air mass in the Rhine valley is better depicted in A00 than in REF00. Similar results are deduced from the vertical cross-section along the Rhine valley at 15 UTC (Fig. 9); the cold pool is moister, colder and thicker in A00 than in REF00. However, the föhn reaches the ground a few kilometres further in A00, just near Buchs-Grabs. The intensity of the mountain wave, driven by meso-alpha features, is clearly not modified by the mesoscale analysis. The stagnant cold pool, due to the equilibrium between radiative cooling and warming and turbulent mixing, benefits longer from the mesoscale analysis. This long time benefit depends also on the model diffusion, which can destroy this weak equilibrium. In our case, we conclude that the mesoscale initialization is of benefit in the first 12 hours of the simulation, and that its benefit is still visible in some regions after 24 hours.

\section{DETAILED ANALYSIS FROM THE BEST SIMULATIONS}

\section{(a) Heat budget of the cold pool}

In this section we investigate the heat budget of the cold pool using simulation A12 in order to quantify the processes governing the penetration of the föhn, namely

(i) vertical mixing in connection with the diurnal heating of the cold pool,

(ii) turbulent entrainment induced by Kelvin-Helmholtz instability at the top of the cold pool, and

(iii) intensification of the mountain wave.

The evolution of the potential temperature results from an imbalance between the contribution of several physical and dynamical processes, mainly advection, turbulence and radiation. The contribution of the phase changes is negligible here and the corresponding terms are not considered in the budget equation. However, the fourth-order numerical diffusion may locally contribute at a significant level to the potential temperature evolution and has to be taken into account in the budget equation.

The potential temperature budget is obtained by averaging the thermodynamic equation terms over 2 min (18 time steps). Figure 11 presents the dominant terms of the budget at 16 and 22 UTC along the same cross-section as Fig. 9. The radiation term is weaker, and seems to exclude radiation as a main process in the evolution of the cold 


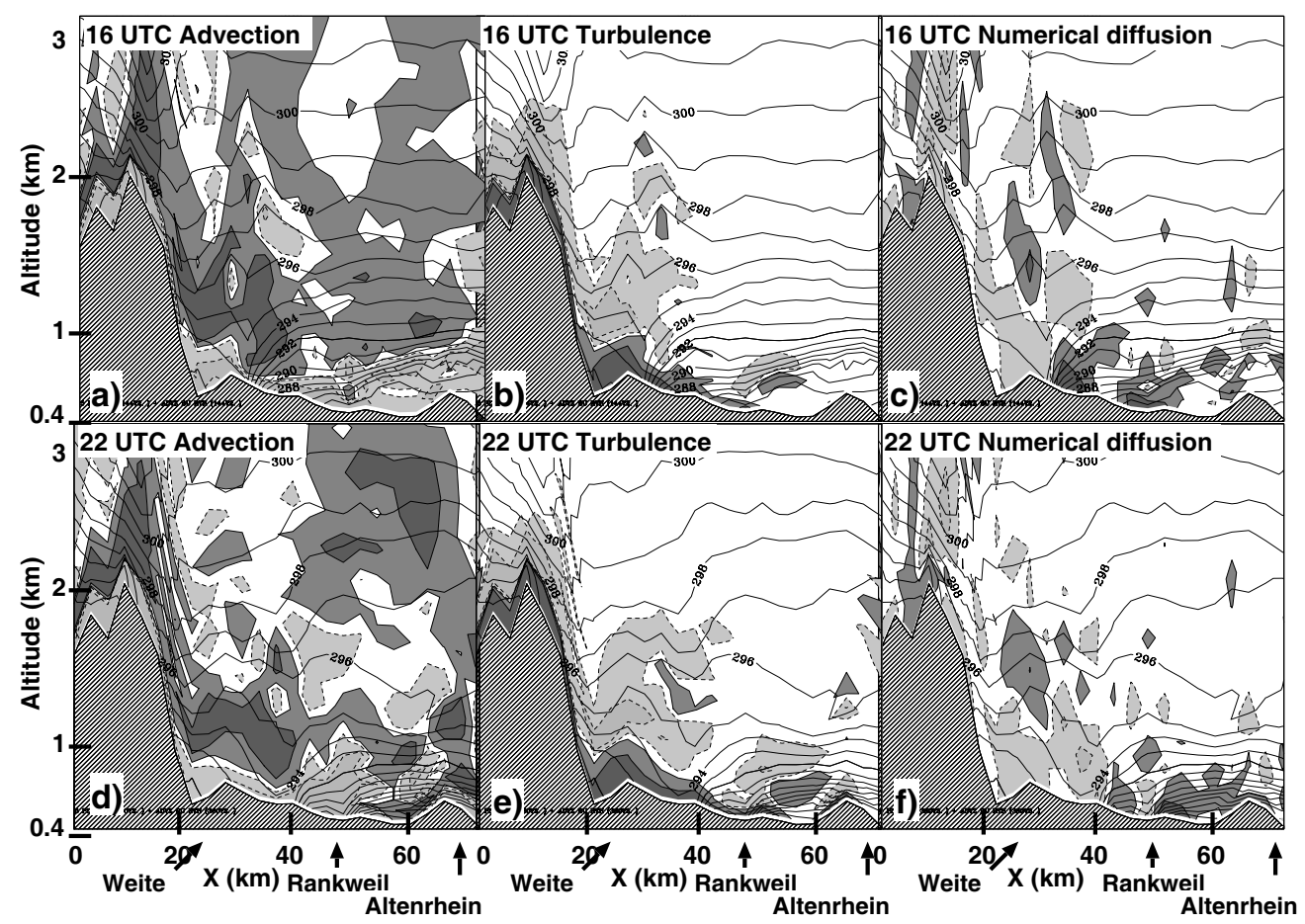

Figure 11. Instantaneous potential temperature budget terms (unit: $10^{-3} \mathrm{~K} \mathrm{~s}^{-1}$ ) at 16 UTC on 5 November 1999 from the A12 simulation along the same cross-section as Fig. 9: (a) advection by the mean flow, (b) turbulent tendency, and (c) numerical diffusion, all with very dark shading above 0.5 , dark shading between 0.1 and 0.5 , light shading between -0.1 and -0.5 , and medium shading below -0.5 . Potential temperature contours are shown on each panel with interval $1 \mathrm{~K}$. (d)-(f) are as (a)-(c), but for 22 UTC.

pool during the evening of 5 November. At 16 UTC, advection by the cold northerly wind near the ground contributes to the cooling of the cold pool just near the ground surface, whereas the warm southerly föhn flow contributes to the warming of the upper layer of the cold pool. The turbulent tendency is important close to the mountain owing to the turbulent nature of the föhn. Turbulence is also important near the valley floor on the foothills of the Alpine range in connection with the föhn touchdown and upward surge south of the cold pool. Turbulence is also active at the leading edge of the cold pool as well as at the secondary bump of the cold pool to the north of Rankweil. So turbulence tends to warm up the lower levels of the cold pool and to cool the top of the cold pool at these specific locations. This is in accordance with the Merlin flight, which documented strong turbulence in its lowest leg at the southern part of its track. Numerical diffusion also mainly contributes to warming the lower levels of the cold pool. At 22 UTC, the dominant terms tend to contribute in the same way. Nonetheless, it can be noticed that the turbulence contribution induced by föhn and the one associated with the cold pool are separated at that time. Also, advection by the northerly flow is limited to the southern low-level part. With these budget analyses, we point out that the intensification of the mountain wave (through the advection term) is the dominant process to erode the top of the cold pool, while the turbulent entrainment induced by Kelvin-Helmholtz instability at the top of the cold pool is more localized. However, the partitioning between the advection and turbulence terms at the southern tip of the cold pool has to be considered with caution, due to the significant numerical diffusion here. 
The diurnal heating of the cold pool cannot significantly contribute, considering the time of the budget analyses presented here. However, this process has been identified as a contributor to the warming of the cold pool during the morning (from REF00 budgets, not shown). Also, after sunset, the influence of radiation in regenerating the cold pool is evident, as one would expect.

\section{(b) Relationship between the föhn and the upstream flow characteristics}

In order to establish a correlation between the föhn behaviour and the upstream flow characteristics, the inverse Froude number (or non-dimensional ridge height) of the upstream flow is computed for the whole duration of the föhn episode. To define the upstream flow, the origin of the air flowing into the Rhine valley was first sought using a back-trajectory technique developed by Gheusi and Stein (2002) (not shown). Because of the non-stationarity of the weather situation, the trajectories are rather complex; they indicate that air parcels were brought to the Rhine valley from the south-east at the beginning of the föhn event (flowing around the secondary low over Sardinia), and then later from the south-west (driven by the main low over northern Europe). However, most of the air was shown to flow along a 'common' final track over the Po valley, between 1500 and $3000 \mathrm{~m}$ amsl, and passing through a $50 \mathrm{~km}$ wide area centred on $45.5^{\circ} \mathrm{N}$, $8.8^{\circ} \mathrm{E}$. The 'upstream' values of the Brunt-Väisälä frequency, $N$, and the upstream normal velocity, $U$, are defined as the average of these quantities over this $50 \mathrm{~km}$ wide area between 1500 and $3000 \mathrm{~m}$, while the ridge height, $H$, was set to $2500 \mathrm{~m}$. The results of this computation are shown in Fig. 12(a)-(c). The upstream air is very stable throughout the episode, with $N$ larger than $0.013 \mathrm{~s}^{-1}$ except after 06 UTC on 6 November. The upstream normal velocity $U$ increased steadily during the period, reaching $10 \mathrm{~m} \mathrm{~s}^{-1}$ at 05 UTC on 6 November, and decreased rapidly after 08 UTC. As a consequence, the non-dimensional mountain height $N H / U$ decreased during the period, after the maximum observed around 17 UTC on 5 November. This maximum is not related to a possible föhn break observed at the valley floor, as the potential temperature simulated above Rankweil increased during this period (Fig. 7(c)). Likewise, the clear minimum $(\mathrm{NH} / \mathrm{U} \approx 3)$ observed at 08 UTC on 6 November came after the end of the föhn event and the maximum of föhn in the Rhine valley occurred at 20 UTC on 5 November, when the inverse Froude number value was close to 5. It appears that, unlike the IOP2 föhn case which occurred in southerly flow conditions (Jaubert and Stein 2003), the southerly component of the inflow did not drive the föhn intensity in the Rhine valley in the IOP15 case. The föhn event is here clearly connected to a flowsplitting regime, which evolved toward a less strongly split regime, in association with the decrease of the inverse Froude number.

The behaviour of the pressure field upstream and downstream of the range was also studied. The reduced pressure at $500 \mathrm{~m}$ altitude at two points located over the Po valley (Lugano) and in the lower Rhine valley (Vaduz) is plotted in Fig. 12(e), together with the difference between these two quantities (Fig. 12(d)) which is related to the pressure drag exerted by the atmosphere on the range (see e.g. Bessemoulin et al. 1993). The REF00 and A12 simulations are both in good agreement with these observations. The pressure difference is roughly proportional to the föhn intensity, as expected from the Bernoulli theorem and from studies of breaking mountain waves. However, no short-time-scale correlations can be found with the variations of the föhn at the ground. Moreover, the time evolutions of the pressure upstream and downstream are rather different; on the upstream side, the pressure decrease is rather smooth and related to the approaching pressure low, but on the downstream side several oscillations are visible, and may be 

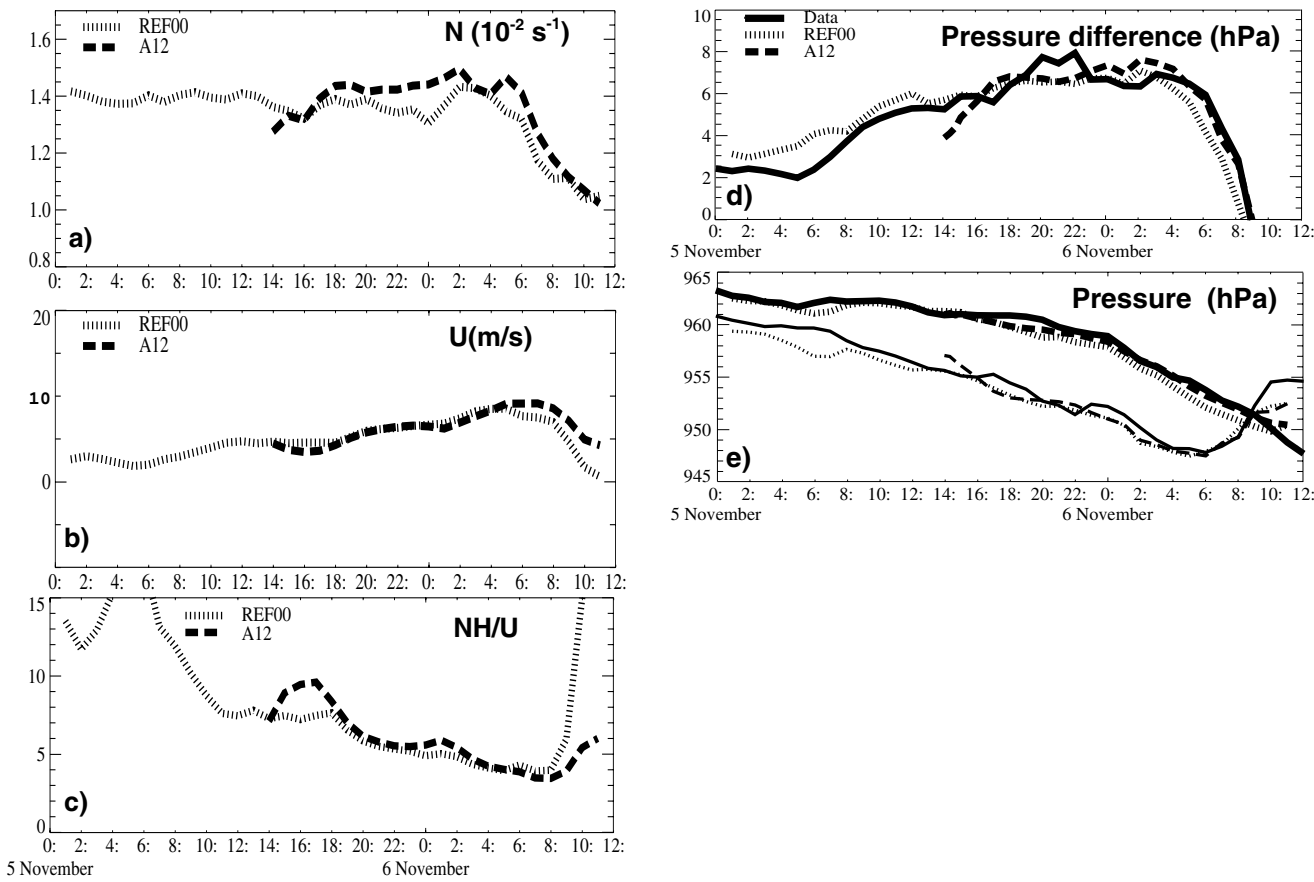

Figure 12. Temporal evolution of (a) the upstream Brunt-Väisälä frequency $\left(10^{-2} \mathrm{~s}^{-1}\right)$, (b) the upstream wind speed $\left(\mathrm{m} \mathrm{s}^{-1}\right)$, (c) the non-dimensional mountain height deduced from (a) and (b), (d) the difference in pressure ( $\mathrm{hPa}$ reduced to $500 \mathrm{~m}$ ) between Lugano in the Po valley and Vaduz in the Rhine valley, and (e) the pressure ( $\mathrm{hPa}$ reduced to $500 \mathrm{~m}$ ) at Lugano (bold) and at Vaduz (thin).

(a)

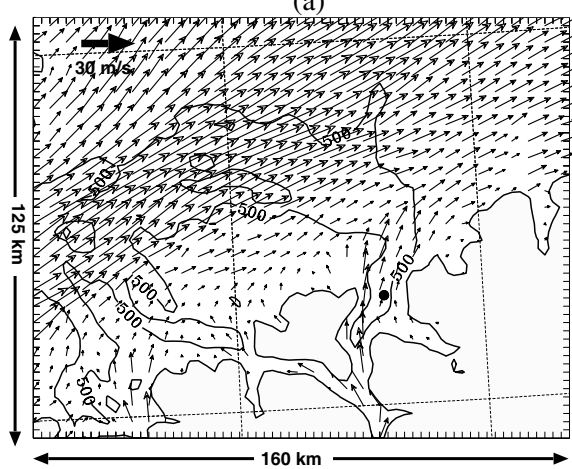

(b)

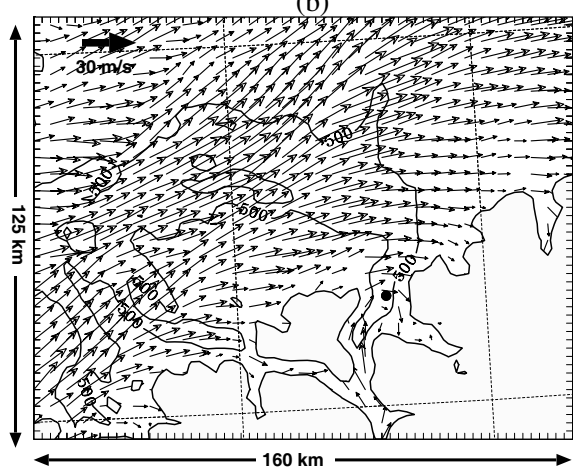

Figure 13. Horizontal wind at $1000 \mathrm{~m}$ amsl at (a) 22 UTC on 5 November and (b) 06 UTC on 6 November 1999 in the area of Lake Constance (domain shown in Fig. 2). Contours are shown at 500 and $1000 \mathrm{~m}$ terrain elevations, and the dot shows the RASS location.

related to the mesoscale variability of the south-westerly flow around the Alps on this side, as will now be shown.

(c) Relationship between the föhn and the south-westerly flow around the Alps

Figure 13 shows the wind field at $1000 \mathrm{~m}$ amsl over the foothills close to the Rhine valley for 22 and 06 UTC during the night of 5/6 November from the A12 simulation. 


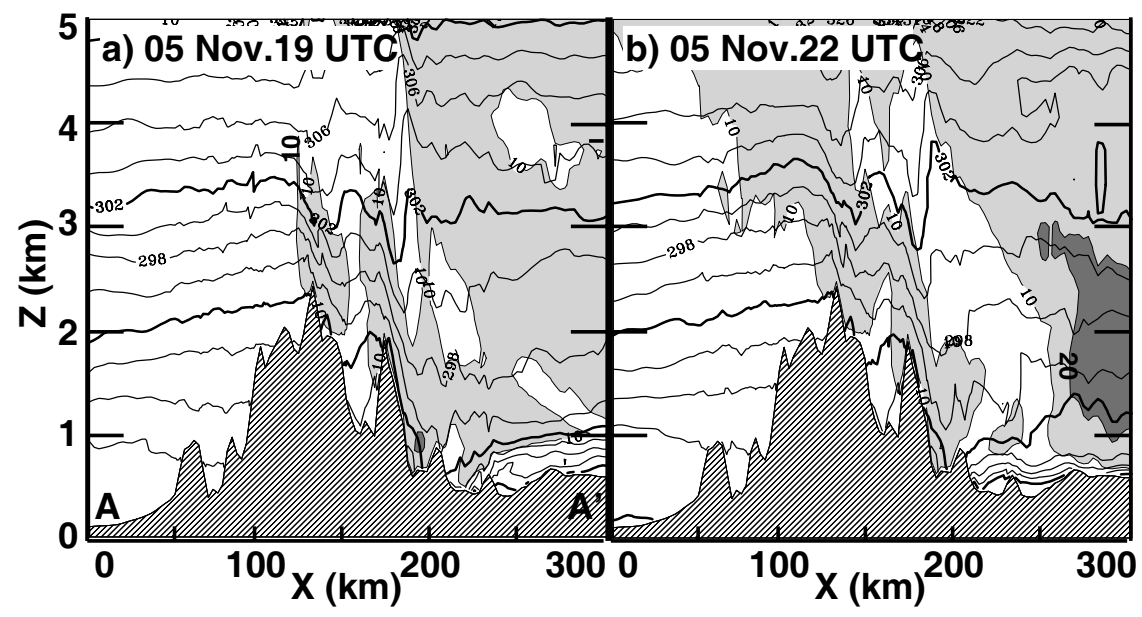

Figure 14. Vertical cross-sections oriented south-north across the Alps and passing through the Rhine valley (see line in Fig. 2) at (a) 19 UTC and (b) 22 UTC on 5 November 1999 (simulation A12, $2.5 \mathrm{~km}$ mesh model): wind speed (at intervals of $10 \mathrm{~m} \mathrm{~s}^{-1}$ with light shading above $10 \mathrm{~m} \mathrm{~s}^{-1}$ and darker shading above $20 \mathrm{~m} \mathrm{~s}^{-1}$ ) and potential temperature with contours every $2 \mathrm{~K}$ (thin solid) and every $8 \mathrm{~K}$ (bold solid).

At 22 UTC, the southerly föhn flow affects all the Rhine valley and extends northwards. A south-westerly wind jet associated with colder air and deviated by the Alps interacts with the föhn jet to produce a pronounced convergence zone downstream of the Alps. The position of this south-westerly jet changes quite substantially during the night in response to the eastward progression of the primary low over northern Europe. It comes close to Lake Constance at 22 UTC, then drifts to the north. At 06 UTC, it has been replaced by the colder westerly flow associated with the cold front that progressed rapidly to the east. This will soon bring the föhn episode to an end. These features are close to those described by Zängl et al. (2004) just before the passage of a shallow cold front and the sudden break-up of the föhn in the lower part of the Rhine valley.

This is further documented by a series of vertical cross-sections of wind and temperature across the range at 19 and 22 UTC (Fig. 14). At 19 UTC, there is a classical mountain-wave pattern with a maximum southerly wind just downstream of the range. At 22 UTC, this pattern is perturbed by cold air associated with the west-south-westerly jet (on the northern side of the range, with intensity of more than $20 \mathrm{~m} \mathrm{~s}^{-1}$ at $2 \mathrm{~km}$, Fig. 14(b)). At 01 UTC (not shown), the flow veers to a more southerly component and the jet is located $35 \mathrm{~km}$ north of the Rhine valley. These temporal variations in low-level flows explain the oscillations of the downstream pressure (see section 4 (b)).

The local topography also plays an important role in the detail of this evolution near the ground surface. Figure 15 displays the topography around Lake Constance, together with the horizontal wind field at $600 \mathrm{~m}$ amsl. Figure 16 shows potential temperature and the wind component perpendicular to the cross-section along two cross-sections, S1 and S2, running east-west. The orography along the cross-section S1 (Fig. 16(a)) is characterized by a $450 \mathrm{~m}$ amsl plateau to the west of Lake Constance, whereas to the east of the lake, a north-south oriented hill (summit $800 \mathrm{~m}$ amsl) can act as an obstacle in appropriate conditions. For example, when south-westerly winds increase to the north of the Alps, the cold-air pool over Lake Constance cannot drift to the east because of the barrier effect of the hill. It is then forced to enter the Rhine valley and interacts with the föhn flow. This phenomenon is clearly illustrated at 21 UTC 
(a)

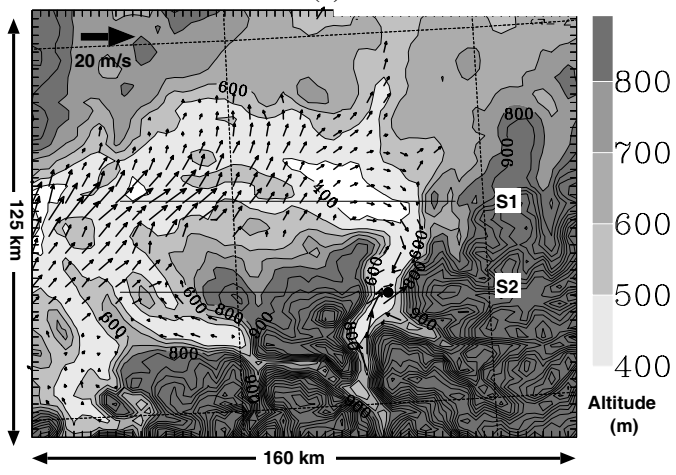

(b)

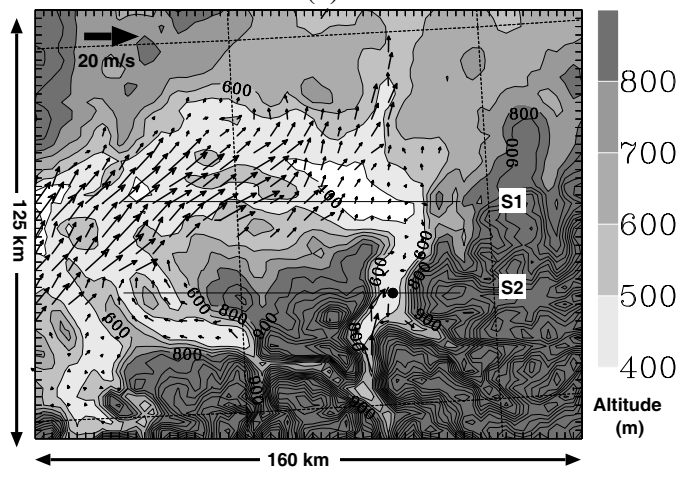

Figure 15. Horizontal wind at $600 \mathrm{~m}$ amsl superimposed on terrain elevation (shading) at (a) 21 UTC and (b) 22 UTC on 5 November 1999 in the area of Lake Constance (domain shown in Fig. 2). The thin east-west lines $\mathrm{S} 1$ and S2 mark the lines of cross-sections in Fig. 16.

(a)

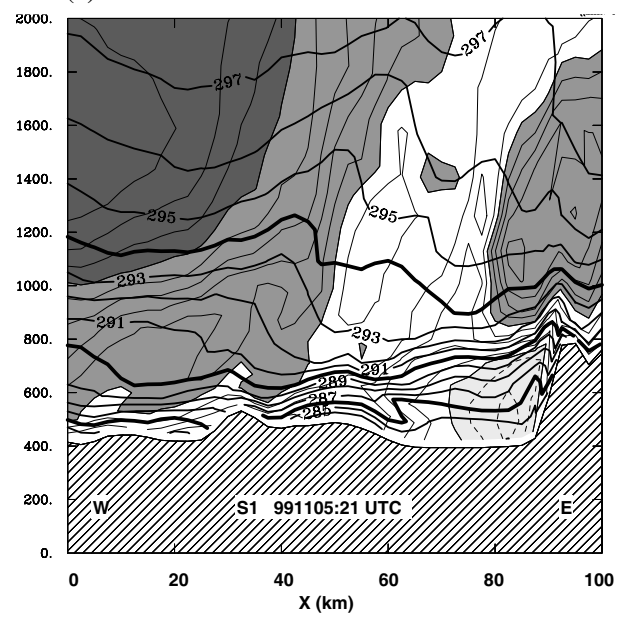

(b)

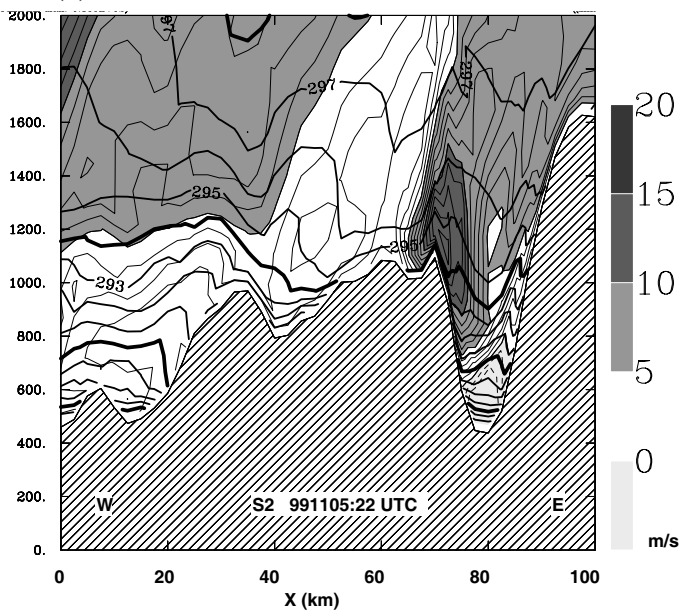

Figure 16. Cross-sections oriented west-east of potential temperature (contour interval $1 \mathrm{~K}$ with bold line every $4 \mathrm{~K}$ ) and wind component perpendicular to the cross-section over (a) Lake Constance at 21 UTC (line S1, Fig. 15) and over (b) the RASS location at Rankweil at 22 UTC (line S2) on 5 November 1999. The wind contour interval and shading are as in Figs. 9 and 10. 
(Figs. 15(a) and 16(a)). The depth of this northerly flow associated with the cold pool is about $400 \mathrm{~m}$, surmounted by the föhn jet. However this phenomenon is intermittent during the föhn episode, as can be seen for example with Fig. 15(b) one hour later. Same intermittence has been also found between 05 and 06 UTC in the simulation; there exists also some evidence in the observations, as can be inferred for example from the RASS data. These are accompanied by pulsations in the south-westerly flow. The cross-section S2 (passing through Rankweil) shows that there also exists an asymmetry between the western and eastern flanks of the Rhine valley. The cold air coming from the outlet of the Rhine valley affects the bottom of the valley and its eastern flank, whereas the western flank is affected by the warm föhn jet (Fig. 16(b)). It can also be noticed that the south-westerly 'flow around' jet and the föhn jet are separated only by about $20 \mathrm{~km}$.

\section{CONClusion}

The interaction between the cold pool and the föhn in the Rhine valley was well documented during IOP15 of MAP (5 and 6 November 1999) by the important network of instruments involved in the FORM project, as well as by aircraft measurements. The event was simulated using the non-hydrostatic model Meso-NH, with two nested model (meshes 10 and $2.5 \mathrm{~km}$ ) in a two-way interactive mode, with great realism.

The use of a mesoscale analysis and associated detailed orography, over the whole domain of simulation, improves the result. The comparison between simulations A12 and REF12 (guess) shows clearly the impact of the mesoscale analysis by introducing the cold pool that was missing in the large-scale analysis at noon. This effect is not limited to the first hours of the simulation, but is still effective twelve hours after the beginning of the run. First, a realistic cold-pool height prevents the föhn from touching the ground too early, and allows us to simulate an accurate timing of the föhn onset. Second, this simulation represents well the stagnant cold air which remains over the foothills for several hours after the föhn breakdown and its penetration upslope against the föhn flow for few hours, depending of the large-scale forcing.

Analysis of the interactions between the cold pool and the föhn jet above during the late afternoon and evening of 5 November, based on a heat budget approach, shows that the leading terms appear to be the advection by the mean flow and the turbulent tendency, whereas radiation tendency is weak. The turbulent mixing occurs mainly close to the terrain, in the regions where the föhn air subsides in the lee of the mountain range and where it interacts with the cold pool.

At the scale of the Alpine range, the flow regime is a 'flow around' the Alps during the whole event, with an inflow value increasing from $3 \mathrm{~m} \mathrm{~s}^{-1}$ to $10 \mathrm{~m} \mathrm{~s}^{-1}$ and an inverse Froude number larger than 3. The föhn reaches the ground in the Rhine valley north of the Seez valley bifurcation when the surface pressure difference across the Alps is greater than $6 \mathrm{hPa}$. The jet associated with flow splitting at the scale of the Alps and flowing along the western flank of the range influences the altitude of the föhn jet in the Rhine valley. The air passing over the Alpine range (that subsides in connection with the mountain wave) is channelled in the Rhine valley where it encounters the colder and more stable air coming from the north. The 'flow around' jet appears to modulate the intrusions of cold air from the north in the Rhine valley. These intrusions are favoured when the strong flow-around jet is positioned close to the Rhine valley outlet and is oriented orthogonally to it. Local topography, i.e. the small mountain range east of the Lake Constance basin, makes it easier for the air to enter the Rhine valley, due to channelling. 
As the arrival of the föhn at the ground is connected to the intensity of the mountain wave and to the erosion of the cold pool, three ingredients are necessary to forecast it at short range: an accurate mesoscale model, a model resolution sufficient to resolve the topography of the major valleys, and a model initialization of the local features in the valleys. The results of this study show the ability of future mesoscale operational models to forecast this type of event, and stress the importance of adjoining a mesoscale data assimilation to future operational models.

\section{ACKNOWLEDGEMENTS}

The authors would like to thank the scientists of the MAP FORM working group, coordinated by H. Richner, and particularly R. Steinacker, T. Gutermann, B. Bénech, P. Drobinski, M. Furger and R. Werner for fruitful discussions. We would also like to thank the mesoscale team at CNRM, and particularly J. Stein for early suggestions, P. Jabouille for his help in the use of Meso-NH, and V. Ducrocq for her guidance on the use of the mesoscale analysis. The MAP archive is kindly acknowledged for the data management.

Beffrey, G., Jaubert, G. and

Dabas, A.

Bessemoulin, P., Bougeault, P.,

Genoves, A., Jansa Clar, A. and Puech, D.

Bougeault, P., Benech, B.,

Bessemoulin, P.,

Carissimo, B., Jansa, A.,

Pelon, J., Petitdidier, M. and

Richard, E.

Bougeault, P., Binder, P., Buzzi, A., 2001

Dirks, R., Houze, R.,

Kuettner, J., Smith, R. B.,

Steinacker, R. and Volkert, H.

Bouyssel, F., Ducrocq, V., Favot, F., 2002

Nuret, M., Taillefer, F. and

Therry, G.

Calas, C., Ducrocq, V. and

Sénési, $S$.

Colle, B. A. and Mass, C. F.

Drobinski, P., Haeberli, C.,

Richard, E., Lothon, M.,

Dabas, A., Flamant, P.,

Furger, M. and Steinacker, R.

Ducrocq, V., Ricard, D., Lafore, J.-P. and Orain, F.

Ducrocq, V., Lafore, J., Redelsperger, J.-L. and Orain, F.

Flamant, C., Drobinski, P., Nance, L., Banta, R.,

Darby, L., Dusek, J.,

Hardesty, M., Pelon, J. and

Richard, E.

\section{REFERENCES}

2004

1993

1996

2002

2000

1998

2003

2002

2000

2002
Föhn flow and stable air mass in the Rhine valley: the beginning of a MAP event. Q. J. R. Meteorol. Soc., 130, 541-560

Mountain pressure drag during PYREX. Beitr. Phys. Atmos., 66, 305-325

The results of PYREX. La Météorologie, 8, 11-30

The MAP Special Observing Period. Bull. Am. Meteorol. Soc., 82, 433-462

'Hourly mesoscale surface data analysis for nowcasting'. WMO/WRCP Working Group on Numerical Experimentation, available on http://www.cmc.ec.gc.ca/rpn/ wgne/

Mesoscale analyses and diagnostic parameters for deep convection nowcasting. Meteorol. Appl., 7, 145-161

Windstorms along the western side of the Washington Cascade mountains. Part I: a high-resolution observational and modeling study of the 12 February 1995 event. Mon. Weather Rev., 126, 28-52

Scale interaction processes during the MAP IOP12 south föhn event in the Rhine valley. Q. J. R. Meteorol. Soc., 129, 729 754

Storm-Scale Numerical Rainfall Prediction for Five Precipitating Events over France: On the Importance of the Initial Humidity Field. Weather and Forecasting, 17, 1236-1256

Initialization of a fine-scale model for convective-system prediction: a case study. Q. J. R. Meteorol. Soc., 126, 3041-3065

Flow in an Alpine valley during a shallow south föhn event: Observations, numerical simulations and hydraulic analogue. Q. J. R. Meteorol. Soc., 128, 1173-1210 
Flamant, C., Drobinski, P., Protat, A., Benech, B., Chimani, B., Frioud, M. Furger, M., Häberli, C., Jaubert, G., Lothon, M., Mitev, V., Richner, H.,

Steinacker, R., Tschannett, S. and Vogt, $\mathrm{S}$.

Gheusi, F. and Stein, J.

Gubser, S. and Richner, H.

Heimann, D.

Hoinka, K. P.

Hoinka, K. P. and Volkert, H.

Jaubert, G. and Stein, J.

Lafore, J. P., Stein, J., Asencio, N., Bougeault, P., Ducrocq, V., Duron, J., Fischer, C., Héreil, P., Mascart, P., Redelsperger, J.-L., Richard, E. and Vilà-Guerau de Arellano, J.

Lothon, M., Druilhet, A., Benech, B., Campistron, B., Bernard, S. and Saïd, F.

Morcrette, J.-J., Mlawer, E. J., Iacomo, M. J. and Clough, S. A.

Nater, W., Richner, H. and

Saito, K. Phillips, P. D

Schär, C.

Seibert, $\mathrm{P}$.

Stein, J., Richard, E., Lafore, J. P., Pinty, J. P., Asencio, N. and Cosma, $\mathrm{S}$.

Vogt, S. and Jaubert, G.

Zängl, G.

Zängl, G., Chimani, B. and Haeberli, C.
'Föhn/cold-pool interactions in the Rhine valley during IOP15 of the MAP SOP'. In extended abstracts of the ICAM/MAP2003 conference, Brig, Switzerland, available on: http://www.map.ethz.ch/icam2003/418.pdf

Lagrangian description of air flows using Eulerian passive tracers. Q. J. R. Meteorol. Soc., 128, 337-360

'Investigations into mechanisms leading to the removal of the cold pool in föhn situations'. MAP newsletter 15, available on http://www.map.ethz.ch/index.htm

Three-Dimensional Modelling of Synthetic Cold Fronts interacting with Northern Alpine Föhn. Meteorol. Atmos. Phys., 48, $139-163$

Synoptic-scale atmospheric features and föhn. Contrib. Atmos. Phys., 53, 486-508

On the effect of a föhn on cold fronts in the vicinity of the Alps. Boundary-Layer Meteorol., 40, 199-203

1992 Fronts and the Alps: findings from the Front experiment 1987. Meteorol. Atmos. Phys., 48, 51-75

2003 Multiscale and unsteady aspects of a deep föhn event during MAP. Q. J. R. Meteorol. Soc., 129, 755-776

The Meso-NH atmospheric simulation system. Part I : Adiabatic formulation and control simulations. Annales Geophysicae, 16, 90-109

Experimental study of five föhn events during the Mesoscale Alpine Programme: From synoptic scale to turbulence. Q. J. R. Meteorol. Soc., 129, 2171-2194

'Impact of the radiation transfer scheme RRTM in the ECMWF forecasting system'. Newsletter 91, 2-9, ECMWF, Reading, UK

Shear instabilities and their characteristics during föhn. Geophys. Astrophys. Fluid Dyn., 13, 215-223

A numerical study of the local downslope wind 'Yamaji-kaze' in Japan. Part 2: non-linear aspect of the 3-D flow over a mountain range with a col. J. Meteorol. Soc. Japan, 71, 247270

Mesoscale mountains and the synoptic-scale atmospheric dynamics: A review. Pp. 29-42 in Meteorology at the millennium, Academic Press, London, UK

South föhn studies since the ALPEX experiment. Meteorol. Atmos. Phys., 43, 91-103

2000 High-resolution non-hydrostatic simulations of flash-flood episodes with grid-nesting and ice-phase parametrization. Meteorol. Atmos. Phys., 72, 203-221

2004 Föhn in the Rhine valley as seen by a Wind-Profiler-RASS System and comparison with the non-hydrostatic model Meso-NH. Meteorol. Zeitschrift, 13-3, 165-174

Idealized numerical simulations of shallow föhn. $Q . \quad J . R$. Meteorol. Soc., 128, 431-450

Deep and shallow föhn in the region of Innsbruck: typical features and semi-idealized numerical simulations. Meteorol. Atmos. Phys., 83, 237-261

2004 Numerical simulations of the föhn in the Rhine valley on 24 October 1999 (MAP-IOP10). Mon. Weather Rev., 132, 368389 